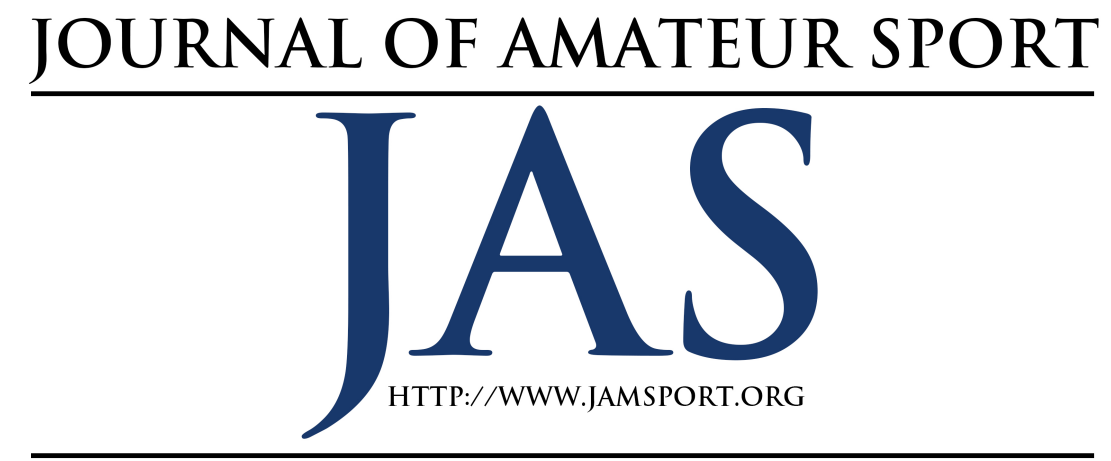

\title{
Investigating the Impact of Team Identification on the Willingness to Commit Verbal and Physical Aggression by Youth Baseball Spectators
}

\author{
Daniel L. Wann \\ Brian Belva \\ Sam Armstrong \\ Murray State University
}

Stephen Weaver

Sagan Ladd

\begin{abstract}
The current investigation was designed to extend previous work on the aggressive actions of youth baseball spectators (Hennessy \& Schwartz, 2007) by incorporating team identification into the research. Team identification, the extent to which a fan feels a psychological connection to a team, (Wann, Melnick, Russell, \& Pease, 2001) has been found to be an important predictor of a wide variety of aggressive actions among sport consumers (Wann, 2006). Spectators $(N=80)$ at youth baseball games completed a questionnaire packet assessing demographics, team identification, vengeance, anger, hostility, and the likelihood of acting in a verbally or physically aggressive manner toward a number of potential targets (e.g., officials, opposing players). Consistent with expectations, team identification predicted a willingness to commit verbally aggressive acts. However, identification did not predict physical aggression.
\end{abstract}

$\mathrm{T}$ he affective, cognitive, and behavioral reactions of sport spectators have drawn the attention of sport scientists for many decades, with some of the first publications dating back to the early 1900s (e.g., Brill, 1929; Howard, 1912; Mumford, 1937; Nash, 1938).

Although researchers have focused on many aspects of fandom, one of the most consistent issues concerns the aggressive and violent reactions sometimes displayed by fans. In fact, the violent actions of sport fans and spectators may be the most often researched topic among social scientists investigating fan reactions (Wann, Melnick, Russell, \& Pease, 2001). Given the large 
volume of work on the subject, it is not surprising then that we have a strong understanding of many facets of fan aggression, including types of aggression (i.e., hostile versus instrumental, see Wann, Schrader, \& Carlson, 2000), forms of aggression (e.g., verbal, physical, property damage, see Wann, Melnick, et al., 2001), hooliganism (Giulianotti, Bonney, \& Hepworth, 1994), and rioting (Mann, 1989; Russell \& Mustonen, 1998; Smith, 1983), to name just a few.

One group of sport fans receiving increased attention in recent years is persons attending youth sporting events. Parents often encourage their children to participate in organized sport because the adults believe that the children will receive tangible benefits from athletic participation. Indeed, a sizeable body of literature now exists to substantiate the parents' beliefs. For instance, youth and/or collegiate sport participation has been linked to reduced risk of suicidal thoughts (Taliaferro, Rienzo, Miller, Pigg, \& Dodd, 2010), increased perceptions of social status (Shakib, Veliz, Dunbar, \& Sabo, 2011), improved selfconfidence (Jones, Dunn, Holt, Sullivan, \& Bloom, 2011), and enhanced self-esteem (Kamal, Blais, Kelly, \& Ekstrand, 1995; Taylor \& Turek, 2010; Wann, 1997). However, parents sometimes exhibit a variety of abusive and/or aggressive behaviors while watching their children compete in athletic events, actions that often result in a negative sport experience for the children (Stahura \& Lough, 2012).
Thus, parents enroll their children in sport in hopes that the youth will find the activity both enjoyable and beneficial. However, many adults then act in an abusive or aggressive manner while watching their child compete, thus eliminating any fun to be had by the children, a pattern of behavior Wann (2012) refers to as the Sport Parent Paradox.

Due to advances in media and social networking, the deviance found in sport is becoming more visible and public (Bass, Vermillion, \& Putz, 2014), and this is most certainly the case with violence at youth sporting events. In fact, research indicates that the extent of spectator aggression at youth sporting events is quite alarming (Shields, Bredemeier, LaVoi, \& Power, 2005; Shields, LaVoi, Bredemeier, \& Power, 2007). In fact, one recent survey found that 84 percent of youth parents had witnessed a violent action from another spectator (Pallerino, 2003). These inappropriate actions are of great concern to those involved in youth sport. For instance, Wiersma and Sherman (2005) conducted a series of focus group interviews with youth sport coaches. The "first and most fervent area" of concern among the volunteers involved "areas of difficulty with parents" (p. 330) and the respondents reported an overwhelming desire and need for a Parent Code of Conduct to help deal with the problem. The problematic parental behaviors do not go unnoticed by the youth athletes. These actions can have a profound effect as recent work suggests that, when 
parents respond inappropriately (e.g., lack sportspersonship), the young athletes are more likely to exhibit inappropriate behaviors themselves (the children often model the adults' poor behaviors, see Arthur-Banning, Wells, Baker, \& Hegreness, 2009; Shields et al., 2007). Furthermore, parents are often unaware of the negative impact they can have on young athletes. They often overestimate their level of support while simultaneously underestimating the pressure they place on the athletes (Kanters, Bocarro, \& Casper, 2008). In addition, youth athletes may be negatively impacted by background anger exhibited between adults (i.e., altercations among parents that do not directly involve a child, Omli \& LaVoi, 2009).

Thus, youth sport parents often exhibit abusive and aggressive behaviors, and these actions can have a negative impact on the athletes. Given this, some authors have examined potential predictors of adult antisocial behavior at youth sporting events (e.g., Engh, 1999; Wann, 2012). Hennessy and Schwartz (2007) examined personal (i.e., individual difference) variables as predictors of spectator aggression at youth baseball games. They asked male and female parents to complete a questionnaire packet assessing vengeance, trait physical and verbal aggression, trait anger, and trait hostility. In addition, participants completed a Spectator Aggression Questionnaire assessing the likelihood they would engage in several forms of verbal and physical aggression toward persons present in the youth sport environment. Specifically, respondents indicated the likelihood that they would yell at, swear at, shove, fight, and humiliate (the aggression types) other spectators, umpires, opposition team coaches, opposition team players, their child's coach, their child's teammates, and their own child (the aggression targets).

The researchers computed a series of regression analyses in which the personal variables (in addition to demographics such as gender) were employed as predictors of likelihood of yelling at and humiliating the targets (regressions were not computed for swearing, shoving, and fighting due to low frequencies of these behaviors). The results indicated several significant effects.

Specifically, yelling at other spectators was predicted by gender (males greater than females) and higher levels of trait anger. Humiliating umpires was predicted by higher levels of vengeance. Finally, higher levels of trait hostility predicted greater likelihood of humiliating a child's teammate. Thus, in various analyses (i.e., among various types and targets of aggression), gender, trait anger, vengeance, and hostility were found to be significant unique predictors of aggressive spectator actions at youth sporting events.

\section{The Current Investigation}

The current investigation was designed to replicate and extend the work of Hennessy and Schwartz (2007). Consistent with their research, we examined potential predictors of the likelihood to engage in 
various verbal and physical acts of aggression among spectators at youth baseball games. With respect to replication, we computed frequency totals for the likelihood of engaging in the aggressive acts, thereby allowing for a comparison between the two data sets. However, we were primarily interested in extending their work on potential predictors by including an additional personal variable not incorporated in their study. Specifically, in addition to including variables found by Hennessy and Schwartz (2007) to be significant unique predictors (i.e., gender, anger, vengeance, and hostility), we also examined the impact of team identification.

Team identification concerns the extent to which a fan feels a psychological connection to a team (Wann, Melnick, et al., 2001). Level of team identification has been found to predict a variety of fan responses including perceptions of influence on the outcomes of sporting events (Kelley \& Tian, 2004; Wann, Dolan, McGeorge, \& Allison, 1994), amount of superstitious behaviors directed toward the team (Wann et al., 2013; Wilson, Grieve, Ostrowski, Mienaltowski, \& Cyr, in press), consumption of team sponsors' products (Madrigal, 2000; Pritchard \& Negro, 2001), and attendance (Bristow \& Sebastian, 2001; Swanson, Gwinner, Larson, \& Janda, 2003). Most germane to the current investigation, however, is the growing volume of work indicating the substantial impact of team identification on sport spectator aggression (Dietz-Uhler \& Lanter, 2008; Wann, 2006).
This body of work has consistently found that identification is a significant and positive predictor of a variety of aggressive reactions among fans. For instance, team identification is positively correlated with expressions of both hostile and instrumental aggression (Wann, Carlson, \& Schrader, 1999) and highly identified fans are particularly likely to aggress against rival fans (Cikara, Botvinivk, \& Fiske, 2011). Highly identified fans are more likely to view verbal aggression as acceptable (Rocca \& Vogl-Bauer, 1999), feel out-of-control at events (Dimmock \& Grove, 2005), and believe that aggressive war-sport analogies are appropriate (End, Kretschmar, Campbell, Mueller, \& Dietz-Uhler, 2003). Furthermore, team identification has been found to play a role in sport rioting (Lanter, 2011). And finally, Wann and his colleagues conducted a series of studies examining fans' willingness to engage in anonymous acts of aggression (Wann et al., 2005; Wann, Haynes, McLean, \& Pullen, 2003; Wann, Peterson, Cothran, \& Dykes, 1999; Wann \& Waddill, 2014). These studies consistently found a positive relationship between identification with a team and willingness to commit anonymous acts.

Given the aforementioned work pinpointing team identification as a key predictor of fan and spectator aggression, we expected similar findings within the youth sport context. Thus, we hypothesized that team identification would account for a significant proportion of unique variance in estimates of likelihood of engaging in verbal 
aggression (Hypothesis 1) and that team identification would account for a significant proportion of unique variance in estimates of likelihood of engaging in physical aggression (Hypothesis 2). With respect to the other variables included in the model (i.e., gender, trait anger, vengeance, and hostility), we chose not to make specific predictions with respect to whether or not they would account for a unique proportion of variance in verbal or physical aggression at youth baseball contests. Although these variables were found to be significant in the original work conducted by Hennessy and Schwartz (2007), specific hypotheses were not warranted for four reasons. First, with respect to physical aggression and swearing, Hennessy and Schwartz did not conduct regressions on these forms of aggression due to low frequency counts. Second, these authors choose to analyze each target individually. To get a more comprehensive picture of youth spectator aggression, we collapsed across target. Third, although Hennessy and Schwartz ran separate regressions for each of the five forms of aggression, we choose to classify the forms as either verbal aggression (i.e., yell at, swear at, and humiliate) or physical aggression (i.e., shove and fight) and to examine total verbal and total physical aggression scores. Again, this was executed to develop a more complete understanding of spectator violence at youth sports. Finally, we examined the impact of additional person variables within the framework of a research question asking, "To what extent does gender, trait vengeance, trait anger, and trait hostility account for a significant proportion of unique variance in the likelihood of verbal and physical aggression of spectators at youth sporting events when team identification is included in the model?"

\section{Method}

\section{Participants}

The original sample consisted of 88 spectators attending a youth baseball game. However, eight respondents failed to return a completed protocol and were removed from the sample. The final sample consisted of 80 persons ( 25 male; 55 female). They had a mean age of 40.63 years $(S D=9.46)$. When asked about the specific child they were watching, most indicated that the child played both recreational baseball and "travel" (i.e., elite) baseball $(60 \%)$. The remaining spectators indicated that the child played only travel $(21 \%)$ or recreational baseball $(19 \%)$. The average age of the players was 10.40 (SD = $2.41 ;$ range $=6$ to 16$)$.

\section{Procedure}

Potential participants were approached prior to a youth baseball game at one of two locations in the mid-south (approval from the institution's IRB and the baseball leagues/facilities was acquired prior to initiating this research). The games were either tournament or regular season contests for either a recreational league or travel teams. Those agreeing to participate (refusal rate was less than 20\%) were given a 
consent letter providing general instructions for the study. Specifically, they were informed that the study was an investigation of adult behaviors at youth sporting events and that the questionnaire packet contained items assessing demographics, personality traits, interest in their child's team, and various fan behaviors. After reading the cover letter and providing their consent, participants were handed an envelope containing the questionnaire protocol and a pencil. They were instructed to complete the questionnaire and to return it and the pencil to the envelope when finished. They were instructed to take their time and complete each item and not to identify themselves in any way on the questionnaire so as to maintain anonymity. Finally, they were told that the research assistant would come back shortly to collect the packet. When the assistant returned, he or she retrieved the envelope, thanked the subject for his or her participation, and handed the respondent a debriefing statement describing the nature and hypotheses of the research. This form contained information on contacting the lead author should the participant have questions or desire a copy of the final report. Completion of the packet required approximately 15 minutes.

\section{Materials}

The questionnaire packet contained five sections, the first of which assessed demographics. Specifically, respondents indicated their age, gender, age of the child the participant was there to watch, and whether the child played travel (elite) baseball, recreational baseball, or both travel and recreational baseball.

Next, participants completed the sevenitem Sport Spectator Identification Scale (SSIS; Wann \& Branscombe, 1993). The SSIS is a reliable and valid tool for assessing team identification that has been successfully used in dozens of studies (Wann, Melnick, et al., 2001) and has been translated into multiple languages including Portuguese (Theodorakis, Wann, Carvalho, \& Sarmento, 2010), Dutch (Melnick \& Wann, 2004), and French (Bernache, Bouchet, \& Lacassagne, 2007). Participants were instructed to target the child's team when completing the SSIS. A sample item read, "How important is being a fan of the child's team to you?" Response options on the Likert-scale SSIS ranged from 1 (low identification) to 8 (bigh identification). Thus, higher numbers represented greater levels of team identification.

The final three sections of the questionnaire were selected because of their inclusion in the work by Hennessy and Schwartz (2007; see also Hennessy \& Schwartz, 2012). Given that the present investigation was both a replication and extension of their work, it seemed reasonable to maintain consistency in scale selection. The third section contained the 20-item Vengeance Scale (VS; Stuckless \& Goranson, 1992). The Likert-scale items on this questionnaire ranged from 1 (strongly disagree) to 7 (strongly agree). As a result, higher numbers corresponded to greater 
levels of vengeance. A sample item on the VS read, "I don't get mad, I get even." The scale has demonstrated reliability and validity and is viewed as "a useful instrument for the examination of individual differences in response to revenge-eliciting situations" (Stuckless \& Goranson, 1992, p. 25).

Section four contained two subscales from the Aggression Questionnaire (Buss \& Perry, 1992), a highly reliable and valid instrument assessing "individual components" of aggression (p. 452). Participants completed the seven-item Anger Subscale (AS) and the eight-item Hostility Subscale (HS). Both subscales were scored on a Likert-scale with response anchors that ranged from 1 (extremely uncharacteristic of me) to 5 (extremely characteristic of $m e$ ). Therefore, higher numbers equated to greater levels of anger and hostility. A sample item on the AS read, "Some of my friends think I am a hothead" while a sample item on the HS read, "I wonder why sometimes I feel so bitter about things."

The final section contained the Spectator Aggression Questionnaire (SAQ) developed by Hennessy and Schwartz (2007). In this measure, participants were presented with a list of seven potential targets of aggression of youth sporting events: another spectator, an umpire, your child's coach, the opposition's coach, an opposing player of your child's team, your child's teammate, and your child.

Participants were asked to indicate how likely they would be to engage in a set of physically and verbally aggressive actions directed at each of the seven targets. The five aggressive acts were: yell at them (verbal aggression), swear at them (verbal aggression), shove them (physical aggression), get into a physical fight (physical aggression), and humiliate them (verbal aggression). Participants were asked "How likely would you be to engage in each of the following with (the target person was inserted here)?" Subjects provided their responses based on a Likert-scale ranging from 0 (not at all likely) to 5 (very likely). Higher numbers reflected a greater likelihood of engaging in the verbally and physically aggressive actions. Thus, the participants completed a total of 35 items (i.e., 7 targets $\mathrm{X} 5$ behaviors $=35$ ).

\section{Results \\ Preliminary Analyses}

Items on the SSIS, VS, AS, and HS were summed to form indices for each scale. Means, standard deviations, and Cronbach's alphas for the measures are listed in Table 1. In addition, an overall Verbal Aggression (VA) score was comprised by summing the 21 SAQ items designed to assess verbal aggression (i.e., likelihood of yelling at, swearing at, and humiliating each of the seven targets). Likewise, an overall Physical Aggression (PA) score was comprised by summing the 14 SAQ items designed to assess physical aggression (i.e., likelihood of shoving and getting into a fight with each of the seven targets). Means, standard deviations, and Cronbach's alphas for the 
VA and PA scales can also be found in Table 1

Correlations were computed between the child's age and team identification, VA, and PA. The results failed to indicate any significant relationships (child's age and SSIS $r=.092, p>.40$; child's age and VA $r$ $=.154, p>.15$; child's age and PA $r=.043$, $p>$.70). Thus, all subsequent analyses were conducted across child's age. In addition, male $(M=37.72 ; S D=6.09)$ and female participants $(M=38.38 ; S D=7.93)$ did not report differential levels of team identification, $F(1,78)=0.14, p>.70$.

\section{Frequency of Likelihood of Engaging in the Aggressive Acts}

The initial series of key analyses involved tabulations of frequency totals for the aggressive behaviors and comparing those with the totals reported by Hennessy and Schwartz (2007). Consistent with the previous work, we computed levels of mean likelihood of engaging in each of the five aggressive responses targeting each of the seven individuals. The scores are listed in Table 2. Also consistent with Hennessy and Schwartz, we computed frequency counts (percentages) of persons indicating at least some likelihood of engaging in the aggressive acts (i.e., persons listing a minimum of 1 on the $0-5$ scale). These totals are listed in Table 3.

A comparison of Tables 2 and 3 with the data presented by Hennessy and Schwartz leads to several interesting conclusions. First, the likelihood scores for the current sample were greater than those previously reported. In fact, every figure reported in Table 2 and 3 matches or exceeds the results found by Hennessy and Schwartz. Second, although the current totals are higher, most are only minimally higher (e.g., almost $60 \%$ of the current likelihood scores were no more than 5\% greater than those reported in the original work). Third, verbal aggression directed toward the umpires and the participant's own child was greater in the current sample. For instance, the average likelihood of yelling at the umpires was 1.15 for the current sample (see Table 2) compared to 0.33 for the Hennessy and Schwartz data set. Likelihood of yelling at one's own child more than doubled in the current study (i.e., 0.86 versus 0.41 ). The increase in verbal aggression aimed at umpires and one's child were also reflected in the other two items assessing verbal aggression (e.g., the likelihood score of 0.17 for swearing at an umpire in the current sample was substantially higher than the score of 0.03 reported previously) and in the percentage of persons reporting a minimal likelihood (see Table 3). For instance, in the current sample, $59 \%$ of participants reported at least a minimal likelihood of yelling at the umpires while $50 \%$ reported at least a minimal likelihood of yelling at their own child, compared to $21 \%$ and $27 \%$, respectively, for the previous sample.

\section{Test of Hypotheses: Impact of Team Identification}


The primary purpose of the current investigation was to extend the work of Hennessy and Schwartz (2007) by investigating the impact of team identification on estimates of likelihood of engaging in the aggressive acts. Correlations among the critical variables appear in Table 4. The hypotheses were tested via a pair of regression analyses in which gender, team identification, vengeance, anger, and hostility were employed as predictor variables and likelihood of verbal (Regression 1) and physical aggression (Regression 2) were the dependent variables. The predictor variables (other than team identification) were chosen for inclusion because they were found to have had a significant impact in the data set reported by Hennessy and Schwartz.

The first regression targeted likelihood of engaging in the verbally aggressive acts (VA scores). This analysis revealed that the combined effect of the five predictor variables was significant, $F(5,74)=5.27, p$ $<.001$ (see Table 5 for regression statistics). With respect to independent contributions, as hypothesized (Hypothesis 1), team identification accounted for a significant proportion of unique variance in estimates of likelihood of engaging in verbal aggression $(t=2.01, p<.05)$. As expected, higher levels of identification corresponded with higher levels of likelihood of engaging in verbal aggression. With respect to the research question, only one other predictor, vengeance, accounted for a significant proportion of unique variance $(t=2.20, p<$ $.05)$ as higher levels of vengeance corresponded with higher levels of likelihood of exhibiting verbal aggression. Gender, anger, and hostility did not (all ps > $.30)$.

The second regression targeted likelihood of engaging in the physically aggressive acts (PA scores). This analysis revealed that the combined effect of the five predictor variables was not significant, $F(5$, $74)=1.67, p=.15$ (see Table 6 for regression statistics). With respect to independent contributions, contrary to Hypothesis 2, team identification did not account for a significant proportion of unique variance in estimates of likelihood of engaging in physical aggression $(t=0.86, p$ $>$.30). With respect to the research question, only vengeance accounted for a significant proportion of unique variance $(t$ $=2.05, p<.05)$ as higher levels of vengeance corresponded with higher levels of likelihood of exhibiting physical aggression. Gender, anger, and hostility did not (all $p$ s $>.60)$.

\section{Additional Analyses}

In addition to the previously described analyses targeting frequency counts and an examination of the impact of team identification, a series of additional analyses were conducted to further understand participants' likelihood of engaging in the verbally and physically aggressive acts. First, an examination of Table 1 (as well as Tables 2 and 3) suggests that participants 
were more likely to engage in verbal aggression than physical aggression. Thus, we conducted a paired-samples $t$-test to determine if there were statistically significant differences in tendencies to engage in the two forms of aggression. However, it is important to note that there were more verbal aggression items (21) than physical aggression items (14). Therefore, prior to conducting the $t$-test, we multiplied the participants' physical aggression scores by 1.5 to arrive at a scale matching the scoring for the verbal aggression scale (i.e., responses to both scales could range from 0 to 105). The $t$-test confirmed that the respondents were indeed more likely to engage in verbal aggression $(M=5.06 ; S D$ $=10.44)$ than physical aggression $(M=$ $0.71 ; S D=3.44), t(79)=4.66, p<.001$.

Tables 2 and 3 also suggest that certain individuals (e.g., umpires) are more likely to be the target of verbally and physically aggressive acts than are other targets (e.g., players). Thus, we were next interested in further exploring the mean scores to test for significant differences among them. First, scores were calculated for each of the seven targets for both verbal and physical aggression (thus, there were 14 total targets). For instance, verbal aggression directed at other spectators was a summation of the three verbal items targeting spectators (i.e., yell at, swear at, and humiliate). Similarly, physical aggression directed at other spectators was a summation of the two physical items targeting spectators (i.e., shove and fight with them). For both targets of verbal and physical aggression, we conducted a multivariate test followed by a series of specific comparison ( $t$-tests with Bonferroni adjustments). Means and standard deviations for both forms of aggression appear in Table 7 . Concerning the analysis examining verbal aggression, the multivariate test was significant, Wilks' Lambda $F(7,73)=8.22, p<.001$. With respect to specific comparisons among targets, post hoc tests indicated that both umpires and the participant's child were, generally, more likely to be the targets of verbal aggression than the other persons. As for the analysis investigating physical aggression, the multivariate test was not significant, Wilks' Lambda $F(7,73)=1.21, p$ $>.30$. With respect to specific comparisons among targets, post hoc tests failed to indicate differences among any pair of targets.

\section{Discussion}

In recent years, social scientists have begun to focus their attention on the abusive and violent actions sometimes exhibited by youth sport parents (Omli \& LaVoi, 2009; Shield et al., 2007; Wiersma \& Sherman, 2005). The current investigation was designed to extend this work and, in particular, the empirical investigation conducted by Hennessy and Schwartz (2007). In their examination of predictors of spectator aggression at youth baseball games, these authors found that gender, trait anger, vengeance, and hostility were significant predictors of various aggressive 
actions at youth sporting events. We attempted to replicate and extend their research by incorporating an additional individual difference variable, team identification, into the model. The inclusion of identification was warranted by numerous studies indicating a strong positive relationship between identification and spectator aggression (see Wann, Melnick, et al., 2001).

A comparison of the current data with those reported by Hennessy and Schwartz (2007) reveals that the current sample reported greater likelihood scores for the aggressive acts, although most of the differences were small (this pattern generally holds true for comparisons with Hennessy \& Schwartz, 2012, as well). Two exceptions to this pattern involved participants' verbal aggression (yelling and swearing) directed toward umpires and their own child in which the current totals were much greater than previously reported by Hennessy and Schwartz. Thus, both umpires and parents' own children were disproportionality likely to be the targets of the parents' verbal aggression. With respect to verbal abuse directed toward the participants' children, it stands to reason that many (if not most) of these outbursts are the result of the child's perceived poor performance. Recent research indicates that there are a number of strategies that parents utilize to cope with the shame they may feel in response to a bad performance by their child athlete (Partridge, Wann, \& Massengale, 2012). These strategies include attacking others (e.g., other players), attacking oneself (e.g., self-blame), and withdrawal. The current data (and those presented by Hennessy and Schwartz) indicate that it is also common for parents to directly attack their children (verbally). As for umpires, given that these persons are responsible for decisions that influence the outcome of a contest, it is perhaps not surprising that these individuals would be frequent targets of verbal harassment. Indeed, prior work with sport spectators at college events has found that the officials are frequent objects of verbal aggression (Wann, Carlson, et al., 1999; Wann et al., 2000). The current findings suggest that this pattern generalizes beyond college athletics into the arena of youth sports.

Although comparisons between the data provided by Hennessy and Schwartz (2007) and the current study are informative, the primary goal of this investigation was to investigate the impact of team identification. Prior to discussing the impact of identification, it warrants mention that identification scores for this sample were quite high. In fact, the mean identification score reported here (slightly above 38) would be classified as moderately high (see Wann, Melnick, et al., 2001) and is comparable to studies asking participants to report their level of identification with their favorite sport team (e.g., Wann, Ensor, \& Bilyeu, 2001; Wann \& Martin, 2008). Thus, it is apparent that the participants felt a strong connection to their child's youth baseball teams. 
With respect to predictors of verbal aggression, as predicted in Hypothesis 1, identification accounted for a significant proportion of unique variance. In terms of the research question, the only additional significant predictor was vengeance. Thus, consistent with past work among sport spectators (see Dietz-Uhler \& Lanter, 2008; Wann, 2006; Wann, Melnick, et al., 2001), higher levels of team identification corresponded with higher levels of verbal aggression. It appears that the oft found positive relationship between identification and verbal aggression extends to the realm of youth baseball as well. Vengeance scores also predicted higher levels of verbal aggression. This finding generally replicates the data presented by Hennessy and Schwartz (2007) who found vengeance to be a significant predictor of humiliation of umpires.

The fact that higher levels of identification predicted greater levels of verbal aggression has implications for youth sport administrators. At first glance, such a finding may lead one to conclude that we should reduce levels of identification parents feel for their child athletes and teams. However, as noted elsewhere (Wann, 2012), it seems unlikely that such attempts would be successful given that parents already strongly identify with their offspring and, in a more practical sense, it seems unwise to suggest to parents that they should care less about their children. Rather, it seems that the best solution available to youth sport coaches and administrators is to alter the form of identification felt by parents. That is, rather than encouraging identification that is focused on outcomes (e.g., winning, making an all-star team, acquiring a college scholarship), identification should focus on the fun and enjoyment experienced by the players (Wann, 2012). By shifting the focus of the identification, youth sport leaders should be able to reduce the importance placed on outcomes while increasing the focus on fun, skill improvement and the like. The result should be that parents maintain high levels of identification with their children while exhibiting lower levels of verbal aggression.

With respect to predictors of physical aggression, contrary to expectations (Hypothesis 2) identification did not account for a significant proportion of unique variance. However, vengeance was again a significant predictor with those having higher vengeance scores reporting a greater likelihood of engaging in the aggressive acts. It may be that identification has a greater influence on verbal aggression than physical aggression. Such a possibility is substantiated by work indicating that, although level of identification predicts perceptions of the appropriateness of verbal aggression among sport fans, no such relationship is found for physical aggression (Rocca, \& Vogl-Bauer, 1999). Conversely, level of fan dysfunction (i.e., the extent to which a fan complains and is confrontational, see Wakefield \& Wann, 2006) has been shown to be a significant positive predictor of perceptions of the 
appropriateness of physical aggression (Donahue \& Wann, 2009).

\section{Additional Findings}

A few additional findings warrant specific mention. First, it is interesting to note that gender was not found as a significant predict of either verbal or physical aggression. This finding is contrary to numerous empirical investigations (including Hennessy \& Schwartz, 2007) indicating greater levels of aggression from males (Baron \& Richardson, 1994; Russell, 2008). The precise reason for this inconsistent finding in unclear and additional research is required to see if this pattern replicates in future work or, rather, if it was simply an artifact of the current investigation.

A second demographic variable, child age, was also found to be unrelated to both verbal and physical aggression as well as level of identification. Thus, parents' psychological connection to their child's team and the frequency with which they were likely to act in an aggressive fashion was not related to their age. One may have expected that each of these variables would be positively correlated with child age. That is, one may have expected parents of older players would report higher levels of identification and aggression, given that the importance of competition and winning would presumably increase as the players get older. However, it appears that parents of children of all ages can experience high levels of identification and display aggressive reactions.

A third additional analysis worthy of special mention concerns comparisons between levels of verbal and physical aggression. Participants reported a much greater likelihood of exhibiting verbally aggressive behaviors. In fact, verbal aggression scores were higher for each of the seven targets and the magnitude of the difference was striking (i.e., verbal aggression scores were 5 to 10 times greater than those for physical aggression). The higher likelihood ratings for verbal aggression is consistent with patterns reported in the earlier study (Hennessy \& Schwartz, 2007) as well as more recent work by Cikara and colleagues (2011) examining Major League Baseball fans.

\section{Suggestions for Future Research}

Although the current research extends our understanding of predictors of verbal and physical aggression among youth sport parents, a number of avenues for future research remain. First, both the current investigation and the work by Hennessy and Schwartz $(2007,2012)$ examined reactions of spectators attending youth baseball games. Research indicates that fans of different sports attend events for different reasons (Wann, Grieve, Zapalac, \& Pease, 2008) and different sports elicit different levels of aggression among spectators (Russell, 2008; Wann, Melnick, et al., 2001). Thus, additional work is needed on spectators at other youth events to 
determine if the effects found here are generalizable to other sports. It may be particularly important to examine sports with a greater level of violent content (e.g., youth football and hockey), given that aggressive sports often result in higher levels of spectator aggression (Arms, Russell, \& Sandilands, 1979; Goldstein \& Arms, 1971). Indeed, the fact that a nonaggressive sport was targeted in the current investigation may have led to the lack of significance regarding physical aggression; more aggressive sports may have resulted in a different outcome.

Hennessy and Schwartz (2012) expanded on their original study in a second investigation by examining the impact of instrumental motivation (the belief that aggressive actions will assist a child's team) and amount of daily life hassles. They found that both level of instrumental motivation and amount of daily hassles were positive predictors of likelihood of aggression at youth baseball games. Combining the current work with the previous efforts by Hennessy and Schwartz $(2007,2012)$ results in an impressive list of important individual difference variables (e.g., team identification, daily hassles, vengeance). However, additional potentially important personal variables have yet to be examined. One such variable is the aforementioned level of fan dysfunction (Wakefield \& Wann, 2006). As noted above, dysfunctional fans tend to be highly confrontational and they are more likely to view both physical and verbal aggression as appropriate (Donahue \& Wann, 2009). Furthermore, recent investigations have found that dysfunctional fans were likely to be bullies as children (Courtney \& Wann, 2010) and often report a particularly high willingness to commit anonymous acts of aggression (Wann \& Waddill, 2014). Given the mounting evidence that fan dysfunction is related to higher levels of aggression, future research should add this variable (along with factors such as identification and vengeance) in future examinations of the aggressive actions of youth sport spectators.

Third, as described above, a number of studies have targeted the willingness of sport fans to engage in anonymous acts of aggression directed at opposition players, coaches, and fans (Wann et al., 2005; Wann et al., 2003; Wann, Peterson, et al., 1999; Wann \& Waddill, 2014). Taken as a whole, these studies indicate that a sizeable minority of fans readily admit a willingness to consider the aggressive acts and that persons with higher levels of identification and dysfunction are especially likely to do so. Future researchers may want to extend this line of work by examining the extent to which spectators at youth sporting events also express a willingness to act in an anonymously aggressive fashion.

Finally, although the current work shed light on the frequency of aggressive acts among youth sport spectators, the motives underlying the actions were not examined. The aggressive actions of sport consumers are often classified as either hostile (the goal 
of the act is the pain and suffering of the victim) or instrumental (the goal is something other than the victim's suffering) (see Wann, Melnick, et al., 2001). Previous work indicates that sport spectators report that both motives underlie their aggressive actions (Wann, Carlson, et al., 1999; Wann et al., 2000). Future research should attempt to determine if the aggressive actions of youth sport parents tend to be hostile or instrumental (or both) in nature. For instance, it would be informative to learn if the verbally abusive shouts of youth spectators are designed to assist the team in some manner (e.g., intimidate the opposition so their performance will decline) or simply to harm the target in some way.

\section{Limitations}

Several limitations of the current work warrant mention. First, as noted above, the current work focused on only one sport (baseball) and only one locale (the midsouth). Consequently, researchers need to replicate the work reported here to determine the extent to which the findings are applicable to other sports and other settings. In fact, a number of situational factors in addition to sport and locale could be valuable to examine, including competition level (see below), game context (e.g., regular season versus playoff), and perhaps even the gender of the player. In addition, although the current work was able to document the strong connection parents felt for their child's team (i.e., the adults' high levels of team identification), we did not ascertain the factors underlying these high levels of identification. Thus, the exact causes are unknown at this time and additional research is needed in this regard.

It is also important to note that the current work focused on willingness to engage in the verbally and physically aggressive acts rather than actual aggressive responses. Thus, this study was more interested in attitudes about aggression than actual overt actions, which may limit the generalizability of the findings. Although past work does show a correspondence between attitudes and behavior (Kraus, 1995) and methodologies such as those employed in the current research are valid (Russell \& Baenninger, 1996), it remains possible that some participants may have misjudged their likelihood of exhibiting the aggressive acts. That is, perhaps some persons understated the likelihood of acting violently due to concerns with social desirability. Likewise, others may have underestimated the likelihood because they failed to consider the powerful situational forces occurring in "the heat of the moment". This latter line of thinking has empirical merit as the vast majority of sport spectators do not attend events expecting to act in an aggressive fashion (indeed, fandom and trait aggression are not significantly correlated, see Russell \& Goldstein, 1995; Wann, Fahl, Erdmann, \& Littleton, 1999). Rather, the situation pairs the game and their high level of team identification and results in a state in which they have less 
control over their actions, something fans readily admit (Dimmock \& Grove, 2005). Additionally, this may help explain the lack of relationship between identification and willingness to commit physical aggression (i.e., persons may be less likely to believe that they would physically harm someone, underestimating the power that situational and personal forces may have in such environments).

However, perhaps the greatest limitation of the current research is found in the small sample size $(n=80)$. First, it may be that the limited number of males played a role in the lack of gender differences found in the current work. Second, although we assessed the level of competition played by the target youth (i.e., travel versus recreational), our small sample size rendered comparisons among these groups inappropriate. Given that pressure may be greater for those involved with elite baseball (both on players and parents), future efforts should acquire larger samples enabling the researchers to test for level of competition as a potential moderator of parent aggression.

\section{Conclusion}

Aggression among parents and other spectators is a major concern for persons involved with youth sports (Shields et al., 2005; Wiersma \& Sherman, 2005).

Although past work had furthered our understanding of various personality and demographic factors related to aggression among youth sport viewers (Hennessy \&
Schwartz, 2007, 2012), the current research extended past efforts by including team identification in the analyses, a subject variable often associated with higher levels of sport spectator aggression (Wann, Melnick, et al., 2001). As hypothesized, identification was a significant predictor of willingness to commit verbal aggression but, contrary to expectations, no such pattern was found for physical aggression. Although not without limitations (e.g., assessment of willingness to aggress rather than overt behavior, small sample size), the data reported above extend our understanding of the predictors of aggression among youth sport parents and, thus, have implications and value for youth sport administrators. 


\section{References}

Arms, R. L., Russell, G. W., \& Sandilans, M. L. (1979). Effects on the hostility of spectators viewing aggressive sports. Social Psychology Quarterly, 42, 275-279. Arthur-Banning, S., Wells, M. S., Baker, B. L., \& Hegreness, R. (2009). Parents behaving badly? The relationship between the sportsmanship behaviors of adults and athletes in youth basketball games. Journal of Sport Behavior, 32, 3-18.

Baron, R. A., \& Richardson, D. R. (1994). Human aggression (2nd ed.). New York: Plenum.

Bass, J. R., Vermillion, M., \& Putz, P. (2014). "Going viral": The impact of forced crowdsourcing on coaching evaluation procedures. International Sport Coaching Journal, 1, 103-108.

Bernache, I., Bouchet, P., \& Lacassagne, MF. (2007). Spectators' identification with French sports teams: A French adaptation of the Sport Spectator Identification Scale. Perceptual and Motor Skills, 104, 83-90.

Brill, A. A. (1929). The why of the fan. North American Review, 228, 429-434.

Bristow, D. N., \& Sebastian, R. J. (2001). Holy cow? Wait 'til next year! A closer look at the brand loyalty of Chicago Cubs baseball fans. Journal of Consumer Marketing, 18, 256-275.

Buss, A. H., \& Perry, M. (1992). The Aggression Questionnaire. Journal of Personality and Social Psychology, 63, 452459.
Cikara, M., Botvinivk, M. M., \& Fiske, S. T. (2011). Us versus them: Social identity shapes neural responses to intergroup competition and harm. Psychological Science, 22, 306-313.

Courtney, J. J., \& Wann, D. L. (2010). The relationship between sport fan dysfunction and bullying behaviors. North American Journal of Psychology, 12, 191-198.

Dietz-Uhler, B., \& Lanter, J. R. (2008). The consequences of sports fan identification. In L. W. Hugenberg, P. M. Haridakis, \& A. C. Earnheardt (Eds.), Sports mania: Essays on fandom and the media in the $21^{\text {st }}$ century (pp. 103113). Jefferson, NC: McFarland. Dimmock, J. A., \& Grove, J. R. (2005). Relationship of fan identification to determinants of aggression. Journal of Applied Sport Psychology, 17, 37-47.

Donahue, T., \& Wann, D. L. (2009).

Perceptions of the appropriateness of sport fan physical and verbal aggression: Potential influences of team identification and fan dysfunction. North American Journal of Psychology, 11, 419-428.

End, C. M., Kretschmar, J., Campbell, J., Mueller, D. G., \& Dietz-Uhler, B. (2003). Sports fans attitudes toward war analogies as descriptors of sport. Journal of Sport Behavior, 26, 356-367.

Engh, F. (1999). Why Johnny hates sports.

Garden City Park, NY: Avery. Giulianotti, R., Bonney, N., \& Hepworth, M. (Eds.). (1994). Football, violence, and 
social identity. London: Routledge.

Goldstein, J. H., \& Arms, R. L. (1971). Effects of observing athletic contests on hostility. Sociometry, 34, 83-90.

Hennessy, D. A., \& Schwartz, S. (2007). Personal predictors of spectator aggression at little league baseball games. Violence and Victims, 22, 205215.

Hennessy, D. A., \& Schwartz, S. (2012). The influence of instrumental motives and daily hassles on spectator aggression at little league baseball games. In B. M. O’Connor (Ed.), Social and psychological issues in sports (pp. 95-114). Hauppauge NY: Nova.

Howard, G. E. (1912). Social psychology of the spectator. American Journal of Sociology, 18, 33-50.

Jones, M. I., Dunn, J. G. H., Holt, N. L., Sullivan, P. J., \& Bloom, G. A. (2011). Exploring the '5Cs' of positive youth development in sport. Journal of Sport Behavior, 34, 250-267.

Kamal, A. H., Blais, C., Kelly, P., \& Ekstrand, K. (1995). Self-esteem attributional components of athletes versus nonathletes. International Journal of Sport Psychology, 26, 189-195.

Kanters, M. A., Bocarro, J., \& Casper, J. (2008). Supported or pressured? An examination of agreement among parents' and children on parents' role in youth sports. Journal of Sport Behavior, 31, 64-80.

Kelley, S. W., \& Tian, K. (2004). Fanatical consumption: An investigation of the behavior of sports fans through textual data. In L. R. Kahle \& C. Riley (Eds.) Sports marketing and the psychology of marketing communication (pp. 27-65). Mahwah, NJ: Lawrence Erlbaum.

Kraus, S. J. (1995). Attitudes and the prediction of behavior: A metaanalysis of empirical literature. Personality and Social Psychology Bulletin, 21, 58-75.

Lanter, J. R. (2011). Spectator identification with the team and participation in celebratory violence. Journal of Sport Behavior, 34, 268-280.

Madrigal, R. (2000). The influence of social alliances with sports teams on intentions to purchase corporate sponsors' products. Journal of Advertising, 29, 13-27.

Mann, L. (1989). Sports crowds and the collective behavior perspective. In J. H. Goldstein (Ed.), Sports, games, and play: Social and psychological viewpoints (2nd ed., pp. 299-331). Hillsdale, NJ: Erlbaum.

Melnick, M. J., \& Wann, D. L. (2004). Sport fandom influences, interests, and behaviors among Norwegian university students. International Sports Journal, 8(1), 1-13.

Mumford, L. (1937). Ends and means. NY: Harper.

Nash, J. B. (1938). Spectatoritis. New York: Barnes.

Omli, J., \& LaVoi, N. M. (2009).

Background anger in youth sport: A 
perfect storm? Journal of Sport Behavior, 32, 242-260.

Pallerino, M. (2003, March/April). Survey says: End the madness-now. Sporting Kid, 13-14.

Partridge, J., Wann, D. L., \& Massengale, B. (2012, October). An exploration of youth sport parents' experiences with reflected shame. Poster presented at the meeting of the Association for Applied Sport Psychology, Atlanta, GA.

Pritchard, M. P., \& Negro, C. M. (2001). Sport loyalty programs and their impact on fan relationships. International Journal of Sports Marketing \& Sponsorship, 3, 317-338.

Rocca, K. A., \& Vogl-Bauer, S. (1999). Trait verbal aggression, sports fan identification, and perceptions of appropriate sports fan communication. Communication Research Reports, 16, 239-248.

Russell, G. W. (2008). Aggression in the sports world: A social psychological perspective. New York: Oxford University Press.

Russell, G. W., \& Baenninger, R. (1986). Murder most foul: Predictors of an affirmative response to an outrageous question. Aggressive Behavior, 22, 175181.

Russell, G. W., \& Goldstein, J. H. (1995). Personality differences between Dutch football fans and nonfans. Social Behavior and Personality, 23, 199204.

Russell, G. W., \& Mustonen, A. (1998).
Peacemakers: Those who intervene to quell a sports riot. Personality and Individual Differences, 24, 335-339. Shakib, S., Veliz, P., Dunbar, M. D., \& Sabo, D. (2011). Athletics as a source of social status among youth: Examining variation by gender, $\mathrm{race} / \mathrm{ethnicity,} \mathrm{and} \mathrm{socioeconomic}$ status. Sociology of Sport Journal, 28, 303-328.

Shields, D. L., Bredemeier, B. L., LaVoi, N. M., \& Power, C. F. (2005). The sport behavior of youth, parents, and coaches: The good, the bad, and the ugly. Journal of Research in Character Education, 3, 43-59.

Shields, D. L., LaVoi, N. M., Bredemeier, B. L., \& Power, F. C. (2007). Predictors of poor sportspersonship in youth sports: Personal attitudes and social influences. Journal of Sport \& Exercise Psychology, 29, 747-762.

Smith, M. D. (1983). Violence in sport. Toronto: Butterworth.

Stahura, K. A., \& Lough, N. (2012). A deconstruction of aggression and violence in youth sport: Theoretical frameworks for explaining behavior. In B. M. O'Connor (Ed.), Social and psychological issues in sports (pp. 169189). Hauppauge NY: Nova.

Stuckless, N., \& Goranson, R. (1992). The Vengeance Scale: Development of a measure of attitudes toward revenge. Journal of Social Behavior and Personality, 7, 25-42. 
Swanson, S. R., Gwinner, K., Larson, B. V., \& Janda, S. (2003). Motivations of college student game attendance and word-of-mouth behavior: The impact of gender differences. Sport Marketing Quarterly, 12, 151-162.

Taliaferro, L. A., Rienzo, B. A., Miller, M. D., Pigg, R. M., \& Dodd, V. J. (2010). Potential mediating pathways through which sports participation relates to reduced risk of suicidal ideation. Research Quarterly for Exercise and Sport, 81, 328-339.

Taylor, M. J., \& Turek, G. M. (2010). If only she would play? The impact of sports participation on self-esteem, school adjustment, and substance use among rural and urban African American girls. Journal of Sport Behavior, 33, 315335.

Theodorakis, N. D., Wann, D. L., Carvalho, M., \& Sarmento, P. (2010).

Translation and initial validation of the Portuguese version of the Sport Spectator Identification Scale. North American Journal of Psychology, 12, 6780.

Wakefield, K. L., \& Wann, D. L. (2006). An examination of dysfunctional sport fans: Method of classification and relationships with problem behaviors. Journal of Leisure Research, 38, 168-186.

Wann, D. L. (1997). Sport psychology. Upper Saddle River, NJ: Prentice Hall.

Wann, D. L. (2006). The causes and consequences of sport team identification. In A. A. Raney \& J.
Bryant (Eds.,) Handbook of sports and media (pp. 331-352). Mahwah, NJ: Erlbaum.

Wann, D. L. (2012, June). Parental involvement in youth sport: Examining appropriate and inappropriate coaching and spectating behaviors. Invited address presented at the Sport Psychology Institute, Portland, ME.

Wann, D. L., \& Branscombe, N. R. (1993). Sports fans: Measuring degree of identification with the team. International Journal of Sport Psychology, 24, 1-17.

Wann, D. L., Carlson, J. D., \& Schrader, M. P. (1999). The impact of team identification on the hostile and instrumental verbal aggression of sport spectators. Journal of Social Behavior and Personality, 14, 279-286.

Wann, D. L., Culver, Z., Akanda, R., Daglar, M., De Divitiis, C., \& Smith, A. (2005). The effects of team identification and game outcome on willingness to consider anonymous acts of hostile aggression. Journal of Sport Behavior, 28, 282-294.

Wann, D. L., Dolan, T. J., McGeorge, K. K., \& Allison, J. A. (1994). Relationships between spectator identification and spectators' perceptions of influence, spectators' emotions, and competition outcome. Journal of Sport and Exercise Psychology, 16, 347-364.

Wann, D. L., Ensor, C. L., \& Bilyeu, J. K. (2001). Intrinsic and extrinsic 
motives for originally following a sport team and team identification. Perceptual and Motor Skills, 93, 451454.

Wann, D. L., Fahl, C. L., Erdmann, J. B., \& Littleton, J. D. (1999). Relationship between identification with the role of sport fan and trait aggression. Perceptual and Motor Skills, 88, 12961298.

Wann, D. L., Grieve, F. G., End, C., Zapalac, R. K., Lanter, J. R., Pease, D. G., Fellows, B., Oliver, K., \& Wallace, A. (2013). Examining the superstitions of sport fans: Types of superstitions, perceptions of impact, and relationship with team identification. Athletic Insight, 5, 21-44.

Wann, D. L., Grieve, F. G., Zapalac, R. K., \& Pease, D. G. (2008). Motivational profiles of sport fans of different sports. Sport Marketing Quarterly, 17, 619.

Wann, D. L., Haynes, G., McLean, B., \& Pullen, P. (2003). Sport team identification and willingness to consider anonymous acts of hostile aggression. Aggressive Behavior, 29, 406-413.

Wann, D. L., \& Martin, J. (2008). The positive relationship between sport team identification and social psychological well-being: Identification with favorite teams versus local teams. Journal of Contemporary Atbletics, 3, 81-91.
Wann, D. L., Melnick, M. J., Russell, G. W., \& Pease, D. G. (2001). Sport fans: The psychology and social impact of spectators. New York: Routledge.

Wann, D. L., Peterson, R. R., Cothran, C., \& Dykes, M. (1999). Sport fan aggression and anonymity: The importance of team identification. Social Behavior and Personality: An International Journal, 27, 597-602.

Wann, D. L., Schrader, M. P., \& Carlson, J.D. (2000). The verbal aggression of sport spectators: A comparison of hostile and instrumental motives. International Sports Journal, 4, 56-63.

Wann, D. L., \& Waddill, P. J. (2014). Predicting sport fans' willingness to consider anonymous acts of aggression: Importance of team identification and fan dysfunction. In C. Mohiyeddini (Ed.), Psychology of motivation, emotions, and actions (pp. 139-151). Hauppauge NY: Nova.

Wiersman, L. D., \& Sherman, C. P. (2005). Volunteer youth sport coaches' perspectives of coaching education/certification and parental codes of conduct. Research Quarterly for Exercise and Sport, 76, 324-338.

Wilson, S. M., Grieve, F. G., Ostrowski, S., Mienaltowski, A., \& Cyr, C. (in press). Roles of team identification and game outcome in sport fan superstitious behaviors. Journal of Sport Behavior. 


\section{Tables}

Table 1

Means, Standard Deviations, and Cronbach's Reliability Alphas for all Measures

Measure

$M$

$S D$

alpha

Team Identification (SSIS)

38.18

7.38

.74

Vengeance (VS)

48.50

17.12

.88

Anger (AS)

15.46

6.28

.84

Hostility (HS)

17.00

7.17

.87

Verbal Aggression (VA)

5.06

10.44

.95

Physical Aggression (PA)

0.48

2.30

.94 
Table 2

Mean Likelihood of Aggressive Actions Directed at the Seven Targets

Aggressive Action

Target Yell at Swearat Shove Fight Humiliate

$\begin{array}{llllll}\text { Another spectator } & .39(.74) & .11(.42) & .05(.22) & .06(.29) & .13(.46) \\ \text { Umpire } & 1.15(1.38) & .17(.69) & .04(.19) & .03(.16) & .15(.53) \\ \text { Opposition coach } & .47(.98) & .12(.64) & .05(.27) & .03(.16) & .13(.46) \\ \text { Child's coach } & .44(1.02) & .09(.43) & .04(.19) & .03(.16) & .11(.53) \\ \text { Opposition player } & .20(.83) & .06(.46) & .03(.16) & .01(.11) & .06(.37) \\ \text { Child's teammate } & .15(.64) & .05(.35) & .01(.11) & .01(.11) & .05(.35) \\ \text { Own child } & .86(1.12) & .09(.58) & .05(.35) & .05(.35) & .08(.38)\end{array}$

Note: Standard deviations appear in parentheses following each mean. 
Table 3

Percentage of Individuals Indicating at Least Some Likelihood of Engaging in the Aggressive Acts

$$
\text { Aggressive Action }
$$

Target

$$
\text { Yell at }
$$

Swear at

Shove

Fight

Humiliate

$\begin{array}{llllll}\text { Another spectator } & 31 & 9 & 5 & 5 & 9 \\ \text { Umpire } & 59 & 8 & 4 & 3 & 10 \\ \text { Opposition coach } & 30 & 6 & 4 & 3 & 9 \\ \text { Child's coach } & 23 & 5 & 4 & 3 & 6 \\ \text { Opposition player } & 9 & 3 & 3 & 1 & 4 \\ \text { Child's teammate } & 9 & 3 & 1 & 1 & 3 \\ \text { Own child } & 50 & 4 & 3 & 3 & 5\end{array}$


Table 4

Pearson Correlations among Gender, Team Identification, Vengeance, Anger, Hostility, Verbal Aggression, and Physical Aggression

\begin{tabular}{|c|c|c|c|c|c|c|c|}
\hline & 1 & 2 & 3 & 4 & 5 & 6 & 7 \\
\hline Gender $(1)^{1}$ & -- & & & & & & \\
\hline Team Identification (2) & .04 & -- & & & & & \\
\hline Vengeance (3) & .05 & .12 & -- & & & & \\
\hline Anger (4) & -.02 & $.24 *$ & $.41^{* *}$ & -- & & & \\
\hline Hostility (5) & 20 & .11 & $.40^{* *}$ & $.65^{* *}$ & -- & & \\
\hline Verbal Aggression (6) & -.03 & $.28^{*}$ & $.39 * *$ & $.39 * *$ & $.35^{* *}$ & -- & \\
\hline Physical Aggression (7) & .02 & .15 & $.29 * *$ & .20 & .15 & $.71 * *$ & -- \\
\hline
\end{tabular}

Notes: ${ }^{1}$ Gender coded as $1=$ male, $2=$ female. $*=p<.05 ; * * p<.01$. 
Table 5

Regression Equation with Gender, Team Identification, Vengeance, Anger, and Hostility as Predictors of Likelihood of Engaging in Verbal Aggression

Predictor variable $\quad B \quad$ SEB $\quad$ Beta $t \quad$ sig.

$\begin{array}{lccccc}\text { Gender } & -1.748 & 2.330 & -0.078 & -0.75 & .455 \\ \text { Team Identification } & 0.295 & 0.146 & 0.208 & 2.01 & .048 \\ \text { Vengeance } & 0.150 & 0.068 & 0.246 & 2.20 & .031 \\ \text { Anger } & 0.240 & 0.233 & 0.144 & 1.03 & .308 \\ \text { Hostility } & 0.211 & 0.203 & 0.145 & 1.04 & .301 \\ \text { Overall } R & 0.513 & & & & \\ \text { Overall } R^{2} & 0.263 & & & & \\ \text { Adjusted } R^{2} & 0.213 & & & & \\ \text { Overall } F(5,74) & 5.274 * & & & & \\ & \end{array}$

Note: $*=p<.001$. 
Table 6

Regression Equation with Gender, Team Identification, Vengeance, Anger, and Hostility as Predictors of Likelihood of Engaging in Physical Aggression

Predictor variable

Gender

Team Identification

Vengeance

Anger

Hostility

Overall $R$

Overall $R^{2}$

Adjusted $R^{2}$

Overall $F(5,74)$
B

SE B

0.565

0.008

0.07

.947

0.031

0.036

0.099

0.86

.390

0.034

0.017

0.253

2.05

.044

0.027

0.057

0.073

0.47

.637

$-0.002$

0.049

$-0.008$

$-0.05$

.961 
Table 7

Mean Likelihood of Verbally and Physically Aggressive Actions Directed at the Seven Targets

Aggressive Action

Target Verbal Aggression Physical Aggression

$\begin{array}{lll}\text { Another spectator } & 0.63^{\mathrm{c}}(1.47) & 0.11^{\mathrm{a}}(0.45) \\ \text { Umpire } & 1.48^{\mathrm{a}}(2.23) & 0.06^{\mathrm{a}}(0.33) \\ \text { Opposition coach } & 0.73^{\mathrm{bc}}(1.86) & 0.08^{\mathrm{a}}(0.38) \\ \text { Child's coach } & 0.64^{\mathrm{bcd}}(1.81) & 0.06^{\mathrm{a}}(0.33) \\ \text { Opposition player } & 0.33^{\mathrm{bcd}}(1.51) & 0.04^{\mathrm{a}}(0.25) \\ \text { Child's teammate } & 0.25^{\mathrm{d}}(1.30) & 0.03^{\mathrm{a}}(0.22) \\ \text { Own child } & 1.03^{\mathrm{ab}}(1.79) & 0.10^{\mathrm{a}}(0.70)\end{array}$

Note: Standard deviations appear in parentheses following each mean. For each column (i.e., aggression type), means with a common subscript do not significantly differ (alpha $=.002)$. 